
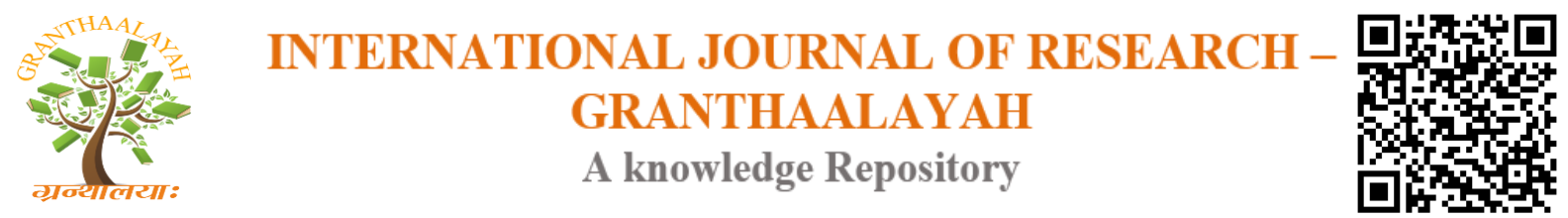

Management

\title{
USE OF INFORMATION SOURCES AND SERVICES IN ACADEMIC LIBRARIES
}

\author{
Aftab Khan ${ }^{* 1}$, Dr. Javed Khan ${ }^{2}$ \\ ${ }^{* 1}$ Research Scholar, Swami VivekanandSubharti University, Meerut, INDIA \\ ${ }^{2}$ Associate Professor, Swami VivekanandSubharti University, Meerut, INDIA
}

DOI: https://doi.org/10.29121/granthaalayah.v4.i10.2016.2490

\section{ABSTRACT}

Information is everywhere. Today, with technology advances and more and more awareness for the need of progress and development, the government is taking a lot of interest in promoting research work and projects. This has become because of the technological advancements and changing information needs of the users. Technology has dominated all spheres of human activity and the libraries are not and exception one. Due to development in technological advancements, sources like electronic journals, e-books, e-databases, pre-prints, numerical and graphical data, library catalogue, educational materials, patents, standards, and so on are available on the Web. So we can say that information is the basic need for the progess and development of nation and humanity.

Keywords:

Academic Libraries, Information Sources, Technology.

Cite This Article: Aftab Khan, and Dr. Javed Khan, "USE OF INFORMATION SOURCES AND SERVICES IN ACADEMIC LIBRARIES" International Journal of Research Granthaalayah, Vol. 4, No. 10 (2016): 53-57.

\section{INTRODUCTION}

\section{CONCEPT OF INFORMATION}

Information is recognized as a vital sources and the basic need, for the progress of humanity and the development of a nation, as a whole. It means that every piece of information should be extracted from wherever it is available and provided to the users at the right time, in the right proportion, without delay of time. Only then, can that piece of information be put to its maximum use. 
Today, with technology advances and more and more awareness for the need of progress and development, the government is taking a lot of interest in promoting research work and projects. All these activities revolve around information."

Information is everywhere. We have to categories it organize it and at the same time let the users know about which source contains what information. Only, when the research scholars know about the contents and whereabouts of information can they use it ease, without having someone to assist them. Now-a-days, subjects are multi-disciplinary in nature because of which, they have become complex. Simultaneously, with the growth in literature there are a number of sources that let us know of the earlier as well as latest developments in a subject. As a result of this growth, the problems of literature explosion have been felt. This tremendous expansion of literature is difficult to be handled or consulted. To make this process easier, attempts have been made to categories to documents, containing information.

\section{LIBRARY SOURCES AND SERVICES}

The information plays vital role in this digital environment. This has become because of the technological advancements and changing information needs of the users. Technology has dominated all spheres of human activity and the libraries are not and exception one. The new storage media have appeared after the invention of storage devices like microforms, magnetic tapes, compact discs etc. have found their places in modern libraries and are playing vital role in storage and dissemination of information. Since the mid-eighties, development in computer technology has established a new platform for the use of information technologies for libraries and information centers. These developments includes spreading of high performance and cost effective computers, local area networks, high bandwidth of internet of internet, digitization of printed information, and high-density storage and distribution media such as CD-ROM's/DVDs. Due to development in technological advancements, sources like electronic journals, e-books, edatabases, pre-prints, numerical and graphical data, library catalogue, educational materials, patents, standards, and so on are available on the Web. Apart from providing lot of information, the web also provides lots of information services like table of content page, electronic document delivery reference service over the web, database access, indexing and abstracting, referral service, bibliographic search and so on. The availability of information in the electronic media has created an opportunity for global access to information.

\section{E- RESOURCES}

Resources are nothing but digital collection meant to provide solution to regular and control the fast rating information explosion in then the recent year. More ever electronic recourses consist of materials that are computer controlled including materials that requires the use of a peripheral attached to computer. and resources are those resources, which is stored electronically and that can be accessible through electronic system and networks there are several types of electronic resources available and these e-resources consists of wide varieties of materials includes information in any electronic form such as CD-ROM, online, data bases, e-Journals e-books, ETD, OPAC, internet resources and any type of digital resources. 


\section{NEEDS OF E-RESOURCES}

We Need E-Resources so that:

- Users may be able to access lattes information

- User can save their time.

- Space problems in library can be solved.

- Easy accessibility and dissemination of them can be done by the users.

- Download can be done instantly.

- Users can read E-resources at any time.

- E-resources can be taking anywhere on portable computer.

- Font size can be changed suitable.

- E-resources provide facility to hold and turn pages easily.

- More interactive in comparison to print media.

- Background music and animation can be done.

- User does not require binding and repair.

- They save human resources for shelving and rectification.

- User cannot misplace e-books.

\section{TYPES OF ELECTRONIC RESOURCES}

- E- DATA BASES

- E- JOURNALS

- E-BOOKS

- OPAC

- CD-ROM

\section{ELECTRONIC DATABASES}

An electronic database consists of electronic controlled access to it by their commercial providers. The first abstracting services such as Biological Abstracts, Index Medicos, Chemical Abstracts, etc. By the year 1988, only half of all databases were bibliographic in nature With introduction of a number of online databases containing textual information, news, statistics commodity prices, etc., a third type of databases holding text of full-length documents started appearing. Several full -text of encyclopedia, directories and articles from journals are now available online. Most of the publishers now provide access to their full-text journals through their web site or through other electronic publishing platforms. While there are a number of public-domain databases, most online databases require annual subscription for accessing them. Thousands of databases are now available on compact discs (CD-ROM) as well as on the Web.

\section{ELECTRONIC JOURNALS}

Electronic journals, or "e-journals", are used for those journals and newsletters that are prepared and distributed electronically. Electronic journals may be defined very broadly as any journal magazine, e-zine, webzine, newsletter or type of electronic serial publication which is available over the Internet and can be accessed using different technologies such as WWW, Gopher, ftp, 
telnet, e-mail or listserv. Several traditional journals are now available on the Web or distributed to subscribers as an e-mail text messages or through technologies like RSS and Atom. Internetbased electronic journals to appear in the beginning of 1990. These journals were mostly delivered as an attachment to -mail while their back issues were mounted on anonymous ftp sites and users were required to download them from these ftp sites. The libraries and information centers made them accessible through their gopher site. 1995 witnessed peak f Gopher technology which then dropped suddenly and dramatically by 1997 . With advent of WWW technology in 1993, electronic publishing became more than a novelty, the web as a means of delivery of electronic information has grown steadily since then. As publisher experiment with different publication modes and models, the very definition of a journal is undergoing change in the electronic environment. New journals have evolved based on the graphic capabilities of the Internet that are available only in electronic form.

Like print journals, current and archival issues of electronic journals can be browsed through their content pages. Moreover, e-journals can also be searched not only on their metadata but also in full-text through sophisticated search interface. Currently, there are more than 50, 000 peer-reviewed scholarly electronic journals that are available on the Internet.

\section{ELECTRONIC BOOKS}

An electronic book is digital reading material that a user can view on a desktop or Personal Digital Assistant (PDA) laptop or on a dedicated, portable device with a large storage capacity and the ability to download new titles via a network connection. More and more traditional book publishers, as well as those catering to the professional and business communities, are launching their e-book collections.

The electronic books market consists of two distinct component i.e. (electronic books consisting of digital material or contents, and ii) electronic book hardware including e-book reading appliance, PCs, laptop or PDA. The digital material or content that can be transported any digital storage media or delivered over a network connection. It designed to be viewed on some combination of hardware and software ranging from dumb terminals to web browsers, on personal computers to the new reading appliances.

\section{OPAC}

Remote access to the library catalogues (OPAC) was possible only through a telnet connection before the Web was launched. The Web-based interfaces are now available for mast of the integrated library software packages including Libsys. Websites are increasingly providing links to their WEBOPAC instead of talent links to their library OPAC.

Exploiting the provisions of hyper linking to other records in a WEB-OPAC are hyperlinks to other records in the database. 


\section{CD-ROM}

Compact disc read only memory (CD-ROM) is plastic disc storage medium. Unlike other storage mediums. Such as tapes, floppy disc. Hard disc etc. Which is based on the principal of magnetism, CD-ROMs are based on the use of light. But, nothing can be written on it. Scientific periodicals, books in print, BNB etc. are now available on CD-ROM.

\section{ADVANTAGES OF E-RESOURCES}

The reasons for actually embarking on the purchasing of electronic resources are generally accepted because of the ease of usability, readability, affordability and accessibility. The following are the advantages of e-resources over the print media

1) Multi-access: A networked product can provide multiple points of access at multiple points in time (24 hours a day. 7 days a week) and to multiple simultaneous users.

2) Speed: An electronic resource is lot quicker to browse or search, to extract information from, and to integrate that information into other material and to cross-search or reference between different publications.

3) Functionality: E-resource will allow the user to approach the publications to analyze its content in new ways by click of the mouse on search mode.

4) Content: The e- resources can contain a vast amount of information, but more importantly the material can consist of mixed media i.e. images, video, audio animation which could not be replaced in print.

\section{REFERENCES}

[1] DawraManisha (2004), "Kinds of Reference Book and Their Evaluation." Sources of Information Page 87-102.

[2] Khan M.T.M (1998) "Sources of Information" Information Organization and Communication pg 16-33.

[3] Khanna, J.K. (1985) Advances in Librarianship, New Delhi. ESS.ESS,.

[4] Kumar Anil and Singh Jasber (2011) "Awareness and Use of Library Information Resources and Services in Different Universities Libraries in Delhi” Journals of Library \& Information Technology Vol. 7 No. 1 pg 19-38.

[5] Prashar, R.G. (1991) Information and its Communication. New Delhi, Medallian,

[6] Vishwanathan, C.G (1976.) Elements of Information Science New Delhi, Today \& Tomorrow 